Špiro Ivošević

Nataša Kovač

Nikola Momčilović

Goran Vukelić

http://dx.doi.org/10.21278/brod72306

ISSN 0007-215X

eISSN 1845-5859

\title{
ANALYSIS OF CORROSION DEPTH PERCENTAGE ON THE INNER BOTTOM PLATES OF AGING BULK CARRIERS WITH AN AIM TO OPTIMIZE CORROSION MARGIN
}

UDC 621.78.019.84:629.546.2

Original scientific paper

Summary

To ensure the better structural integrity and maximum safety of bulk carriers in the ship design phase, an appropriate corrosion margin is introduced by the classification societies, which should enable the exploitation of ships during the projected 25 -year life cycle. The new Common Structural Rules introduce even higher corrosion margin value to ensure the structural integrity of the ship. This directly affects the increase in hull weight and thus the need for more total installed power and higher fuel consumption. Higher fuel consumption results in increased emissions which directly affects environmental pollution. For these reasons, efforts are being made to introduce alternative energy sources, cleaner fuel, ship weight reduction, and the overall economic efficiency of ships. Therefore, using experimental data collected on aging bulk carriers, the paper explores the corrosion margin reduction potential considering its impact on hull weight. Assuming that the corrosive processes occur after four years of operation, a linear model that describes the percentage of plate wear as a function of the as build-in the thickness of inner bottom plates (IBP) of fuel oil tanks (FOT) located on the double bottom of aging bulk carriers, is analyzed. Over the course of 25 years, the IBP segment was monitored on 36 different ships surveys. In this way, 520 input data describing the depth of corrosion were formed. At the same time, records were kept on the mean thickness of the original metal plate, which enabled systematization of the empirical database and grouping of measured values by intervals of original plate thicknesses, and simple conversion of corrosion depth into adequate percentage values. Depth corrosion percentages were represented by standard linear models known in the literature. Based on this analysis, representative numerical and graphical results were obtained. Conclusions from the paper can assist to optimize corrosion margin and the energy efficiency of future vessels.

Key words: $\quad$ ships corrosion; inner bottom plates; corrosion depth; linear model

\section{Introduction}

Corrosion is one of the key mechanisms that accelerate the deterioration of the structural elements of a ship's in service. Accelerated corrosion requires the replacement of corroded 
surfaces even before the planned life cycle of 25 years [1]. For this reason, it is crucial to determine the optimal value of the corrosion margin when designing a ship, so that the corrosion margin is within the allowable limits during the planned life cycle.

Due to serious accidents that have occurred in previous decades, numerous studies have been conducted on bulk carriers and tankers $[2,3]$. Significant research has been conducted in terms of discovering the mechanism of occurrence and development of corrosion and fatigue of different ships structures [4-8]. The analysis of individual structural elements as deck plating, inner bottom plating, transversal bulkheads, girders have been investigated $[4,6,9,10,11]$. Research of individual structure members is important to proposed planning maintenance or conduct different inspection procedures in order to achieve planned ships life cycle $[12,13,14]$.

Optimal determination of corrosion margin can be based on corrosion prediction as well as based on empirical data collected during the life cycle of ships in operation. Numerous influential parameters of the environment, operating conditions, transshipment cargo, maintenance system, and surface protection dominantly affect the operation of the ship and the condition of structural surfaces.

So far, numerous studies have been conducted on extensive databases, to determine the appropriate corrosion margins, which would be added to the projected values during the determination of the calculated thicknesses of structural thicknesses. The most significant research was conducted by Guedes Soares et al. [15], Paik et al. [9-11, 16], Yamamoto and Ikagaki [17], Guo et al. [18], Garbatov et al. [19], Melchers [20], etc.

With the introduction of the New CSR Net Thickness Methodology in 2006, ships are becoming heavier with a significantly increased corrosion margin, and a desire to be as safe as possible, and to guarantee both safety and maximum environmental protection [21].

On the other hand, environmental pollution caused by exhaust emissions is under the attention of the international public with a tendency to reduce it until 2100. Marpol Annex VI seeks to reduce the use of Carbon to zero emission, which supports the desire to reduce environmental pollution. In parallel, efforts are being made to ensure energy efficiency in terms of introducing new energy sources and reducing the consumption of liquid fossil fuels. Alternative energy resource as electricity, liquefied natural gas, compressed natural gas, hydrogen, biodiesel and other can reduce the concentration of anthropogenic greenhouse gases (GHG) in the atmosphere. Furthermore, to reduce Carbon Footprint in the maritime sector, different technical (hull design, power, and propulsion, alternative fuels, alternative energy source) and operation decarbonization measures (optimized maintenance, fleet management, voyage optimization, slow steaming) can be implemented $[22,23]$. Thus, heavier ships require more power in terms of providing the design speed and this is made more difficult by the increased deadweight of ships. In this sense, the aim is to achieve the optimization of the economic efficiency of the ship, through interventions on hull design and optimized maintenance, which is the intention of this paper.

Corrosion margin should be also regarded from the hull steel weight point of view. Optimization of the hull weight becomes more acknowledged especially considering the novel IMO long-term energy efficiency policy where shipping should reduce their total annual GHG emissions up to 50\% until 2050 compared to the 2008 levels [24]. To achieve that IMO has been adopting the short-term policies for newbuilding's (that started from 2013), see [25] and for existing ships (starting from 2023), see [26]. This means, that every cargo ship larger than 400 GT will meet more strengthened criteria on its energy efficiency every several years, expecting large modification of the fleet, since, for example, the majority of current bulk carriers cannot satisfy the anticipating 2023 requirements [26].

Besides alternative fuel and energy savings technologies being explored in that manner, the optimization of the hull appears to be still investigated, particularly concerning the hydrodynamic and hull weight optimizations - where corrosion addition plays a role. Corrosion 
added value of $10 \%, 20 \%$, or $25 \%$ on the calculated net thickness of the element increases its weight proportionally, hence, fine estimations need to be adopted for each structural element, which is to some extent the goal of this paper. Consequently, when considering the global scale of the ship hull: a lighter ship offers more cargo for the same speed and engine power or can transfer the same cargo with reduced engine power and hence, reduced emissions.

From the standpoint of classification societies, the corrosion addition is a value added to the net scantlings of the structural elements (plantings and stiffeners). Net scantlings are calculated according to the prescribed classification societies' formula and strength checks on which the corrosion addition is added to obtain gross scantlings - the ones which would be mounted on the ship. Corrosion addition varies depending on the position of the element, whether there is a fuel tank or ballast tank, etc. Therefore, it is important to properly estimate the corrosion addition especially taking into account its influence on the actual weight of the steel hull. Within the classification societies, the corrosion addition it's given taking into the account ship's life span, which is usually 25 years. However, the corrosion effect is primarily related to the specific part of the ship, loadings, and the maintenance, so the life expectancy of the hull may be considered with reduction and therefore the corrosion addition may be reevaluated.

Accordingly, this paper considers the possibility of reducing or increasing the corrosion margin and optimizing the hull design of the IBP of FOT, based on empirical data collected over aging bulk carriers.

This paper is organized as follows. Section 2 analyses the new common structure rules, data collecting methodology, available database, proposed problem, and related methodology. Section 3 describes the results and Section 4 presents the results obtained.

\section{Materials and Methods}

In this article, we analyze the IBP as a part of FOT located in the double bottom area of aging bulk carriers. Thus, the most important is the common structural rules for the construction of bulk carrier hull structures. During the operation of the ship, rules and regulations issued by classification societies define the minimum scope of thickness measurement, instructions for steel monitoring and repair. Furthermore, rules specify corrosion margin for steel substantial corrosion or steel for renewal.

Considering the structure investigated in this paper, IACS Common Structural Rules for bulk carriers and Oil Tankers [27] state that the corrosion addition for IBP (of the fuel tanks within the double bottom of the bulk carriers) is determined by summation of the corrosion addition from the one side of the plating that acts as a fuel tank, the other side which is exposed to the dry bulk cargo hold and reserve thickness taken to be $0.5 \mathrm{~mm}$, see Table 1 .

Table 1 Corrosion addition for IBP of the bulk carriers according to IACS [27]

\begin{tabular}{|c|c|c|c|c|}
\hline $\begin{array}{c}\text { Type of bulk carriers } \\
\text { according to their class } \\
\text { notations in IACS, }\end{array}$ & $\begin{array}{c}\text { Corrosion } \\
\text { addition - } \\
\text { fuel tank } \\
\text { side }[\mathrm{mm}]\end{array}$ & $\begin{array}{c}\text { Corrosion } \\
\text { addition - dry } \\
\text { bulk cargo } \\
\text { hold side } \\
\text { [mm] }\end{array}$ & $\begin{array}{c}\text { Reserve } \\
\text { thickness } \\
{[\mathrm{mm}]}\end{array}$ & $\begin{array}{c}\text { Total } \\
\text { corrosion } \\
\text { addition } \\
\text { [mm] }\end{array}$ \\
\cline { 1 - 1 } BC-A and BC-B, L>150 m & \multirow{2}{*}{0.7} & 3.7 & 0.5 & 4.9 \\
\cline { 1 - 1 } Other BC & 2.4 & 3.6 \\
\hline
\end{tabular}

The value is constant concerning the calculated net thickness. Therefore, for several assumed net thicknesses of the inner bottom (see Table 2.) the corrosion addition percentage of the final gross scantlings decreases as the net thicknesses increase (see Figure 1.). Bear in mind 
that the minimum allowed total corrosion addition cannot be below $2 \mathrm{~mm}$, according to IACS, 2021. Also, rounding of the gross thickness value is adopted to be 0.5 or $0.0 \mathrm{~mm}$ following the IACS rule, for example: $10.75 \mathrm{~m}<\mathrm{t}<11.25 \mathrm{~mm}$ - adopted is $11 \mathrm{~mm}$. and $11.25 \mathrm{~m}<\mathrm{t}<11.75$ $\mathrm{mm}$ - adopted is $11.5 \mathrm{~mm}$ [27].

Table 2 Corrosion addition percentage and gross thickness for IBP of the bulk carriers calculated according to IACS, 2021

\begin{tabular}{|c|c|c|c|c|c|c|}
\hline $\begin{array}{l}\text { Type of BCs } \\
\text { according to } \\
\text { their class } \\
\text { notations } \\
\text { (see IACS) }\end{array}$ & $\begin{array}{l}\text { The } \\
\text { assumed } \\
\text { net } \\
\text { thickness } \\
\text { of the } \\
\text { plating } \\
\text { [mm] }\end{array}$ & $\begin{array}{c}\text { Total } \\
\text { corrosion } \\
\text { addition } \\
{[\mathrm{mm}]}\end{array}$ & $\begin{array}{c}\text { Gross } \\
\text { thickness } \\
{[\mathrm{mm}]}\end{array}$ & $\begin{array}{l}\text { Corrosion } \\
\text { addition as } \\
\text { a } \\
\text { percentage } \\
\text { of gross } \\
\text { thickness } \\
\text { [mm] }\end{array}$ & $\begin{array}{c}\text { Final } \\
\text { (rounded) } \\
\text { gross } \\
\text { thickness } \\
\text { (see } \\
\text { IACS) } \\
\text { [mm] }\end{array}$ & $\begin{array}{l}\text { Corrosion } \\
\text { addition as a } \\
\text { percentage } \\
\text { of final } \\
\text { gross } \\
\text { thickness } \\
\text { [mm] }\end{array}$ \\
\hline $\begin{array}{l}\text { BC-A, BC- } \\
B, L>150 \mathrm{~m}\end{array}$ & 10 & 4.9 & 14.9 & 0.329 & 15 & 0.333 \\
\hline Other BC & & 3.6 & 13.6 & 0.265 & 13.5 & 0.259 \\
\hline $\begin{array}{l}\text { BC-A, BC- } \\
\text { B, L>150 m }\end{array}$ & 12 & 4.9 & 16.9 & 0.290 & 17 & 0.294 \\
\hline Other BC & & 3.6 & 15.6 & 0.231 & 15.5 & 0.226 \\
\hline $\begin{array}{l}\text { BC-A, BC- } \\
\text { B, L>150 m }\end{array}$ & 14 & 4.9 & 18.9 & 0.259 & 19 & 0.263 \\
\hline Other BC & & 3.6 & 17.6 & 0.205 & 17.5 & 0.200 \\
\hline $\begin{array}{l}\text { BC-A, BC- } \\
\text { B, L>150 m }\end{array}$ & 16 & 4.9 & 20.9 & 0.234 & 21 & 0.238 \\
\hline Other BC & & 3.6 & 19.6 & 0.184 & 19.5 & 0.179 \\
\hline $\begin{array}{l}\text { BC-A, BC- } \\
\text { B, L>150 m }\end{array}$ & 18 & 4.9 & 22.9 & 0.214 & 23 & 0.217 \\
\hline Other BC & & 3.6 & 21.6 & 0.167 & 21.5 & 0.163 \\
\hline $\begin{array}{l}\text { BC-A, BC- } \\
\text { B, L>150 m }\end{array}$ & 20 & 4.9 & 24.9 & 0.197 & 25 & 0.200 \\
\hline Other BC & & 3.6 & 23.6 & 0.153 & 23.5 & 0.149 \\
\hline
\end{tabular}

On the other hand, the classification society has rules and regulations for existing ships with a proposed corrosion margin for a steel to be replaced due to extensive corrosion. Considering rules and regulations for existing ships more classification societies, for bulk carriers consider $20 \%$ to $25 \%$ of allowable diminution from as build-in plate thickness. For some structural areas Classification rules can consider a total reduction of $10 \%$ of whole considered structural areas (deck plating, inner bottom plating, bottom shell, etc.). This is crucially important to achieve an expected ship's life of 25 years.

The type of cargo and the frequency of cargo operations, maintenance optimization, and other influenced factors have a key influence on the condition of IBP. Furthermore, if the corrosion process starts immediately upon exploitation start it is to be expected that it will start earlier for the replacement of corroded surfaces above the permitted acceptable classification permits. Therefore, if there is no data on the cracking of the surface coating and the initial corrosion, it is possible to assume that corrosion begins from 4 to 7 years [28]. In previous 
Analysis of corrosion depth percentage on the inner bottom plates of aging bulk carriers with an aim to optimize corrosion margin
Špiro Ivošević, Nataša Kovač, Nikola Momčilović, Goran Vukelić

research in this field, Paik et al. considered three types of coating life of 5.0, 7.5, and 10 years for different structural areas of bulk carriers [10].

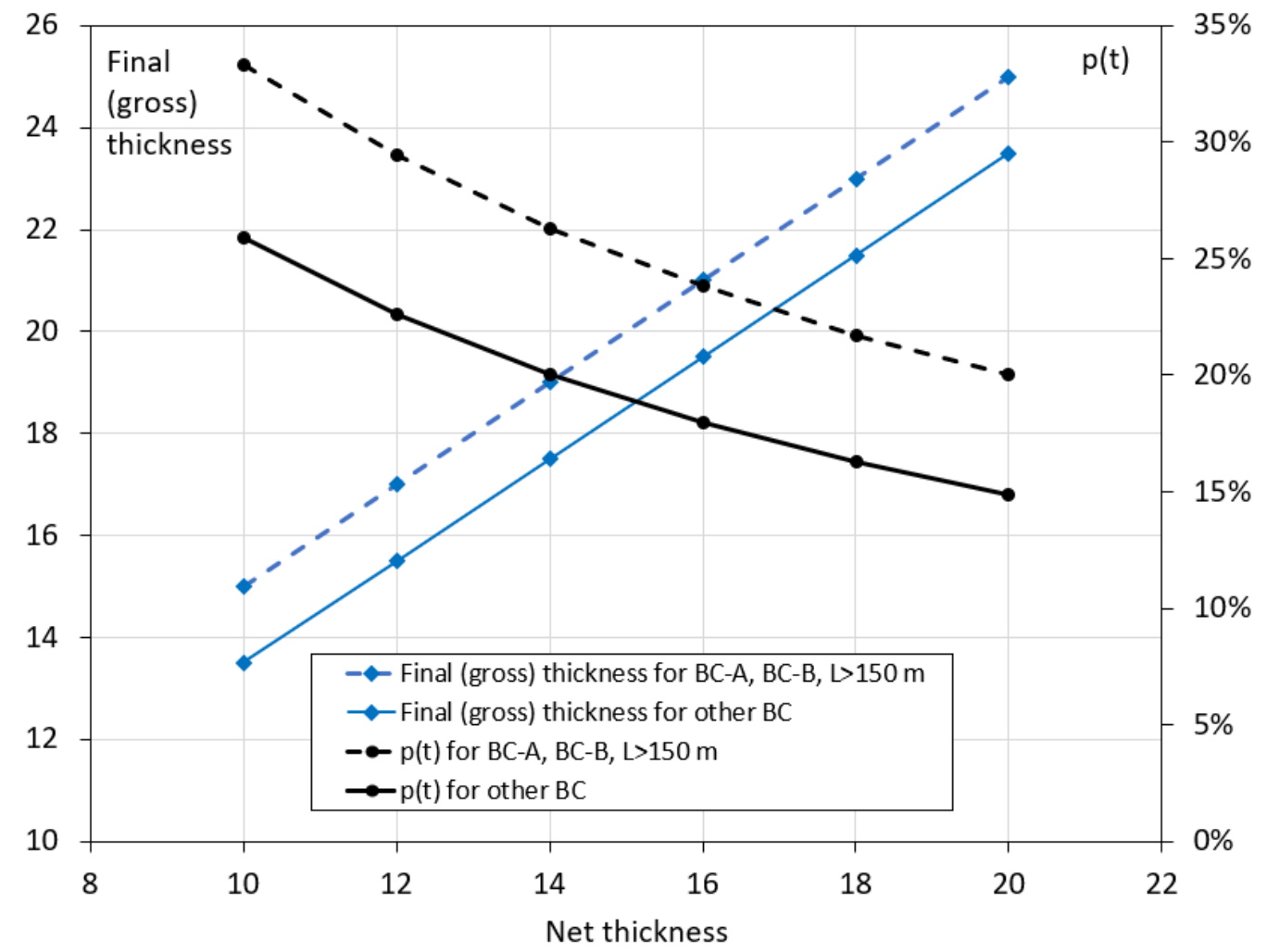

Fig. 1 Gross thickness and corrosion addition percentage plotted against net thickness, for IBP of the bulk carriers according to IACS. 2021

Starting from the assumption that coatings protect metal structures four years after the exploitation starts, with the adequate application of the proposed methodology based on a linear model, moments when $10 \%$ and $15 \%$ of plate loss is reached could be detected. These values are prescribed by classification societies and represent extreme values that enter the zone of potential danger in the exploitation of ships. Analysis and assessment of the percentage wear of fuel oil tanks show that these structural areas cannot be used for 25 years, which is the projected service life of ships.

\subsection{A Brief Description of the Input Data Set}

Based on the previous research by the same author [28-31], the examined database included aging bulk carriers in exploitation whose ages varied between five and twenty-five years. The measured data were gathered between 2005 and 2017, whereby certain bulk carriers were measured one, two, or three times during the ship's special survey.

Following the rules of the classification societies, the structural areas and the intensity of the measurement of structural plates and stiffening depending on the age of the ship are prescribed in detail. Therefore, each special survey requires certain thickness measurements that as a product determine the condition of ships in service. The scope of measurement was arranged by the Classification society and can be minimal (when corrosion does not exist) or increase with the intensity of corrosion and ships age. In this way, with the aging of ships, the number of measured data increases and it is necessary to systematize the data in terms of considering their trend of behavior. In this sense, during each of 36 special surveys, 102 fuel oil tanks were analyzed. Each fuel oil tank cover was considered in such a way that it was determined by the measured values in the imaginary cross-section of the tank (at the ends of tanks and on three same distances between the ends). Each cross-section considers a few 
thicknesses measuring data and the average of these values consist of a total of 520 average thickness reduction data were obtained. These 520 input data values were the subject of further analysis of this article.

As previously indicated, the paper analyzes only bulk carriers whose decay is, over time, caused by general corrosion and expressed as the percentage of the wear of steel plates. Table 3. exhibits the database analyzed - the number of ships surveys concerning their age, the number of fuel oil tanks, number of transverse sections, and available build-in plate thickness of IBP of fuel oil tanks

Table 3 The basic information of fuel oil tanks and their original plate thickness

\begin{tabular}{|c|c|c|c|c|}
\hline $\begin{array}{c}\text { The age of } \\
\text { ships (years) }\end{array}$ & $\begin{array}{c}\text { The number of } \\
\text { ship's surveys }\end{array}$ & $\begin{array}{c}\text { The number } \\
\text { of tanks }\end{array}$ & $\begin{array}{c}\text { The number } \\
\text { of sections }\end{array}$ & $\begin{array}{c}\text { Available build-in plate } \\
\text { thickness (mm) }\end{array}$ \\
\hline $0-5$ & 4 & 9 & 45 & $17-18,22-23$ \\
\hline $5-10$ & 4 & 10 & 50 & $16-17,17-18$ \\
\hline $10-15$ & 7 & 19 & 100 & $16-17,17-18$ \\
\hline $15-20$ & 12 & 39 & 200 & $15-16,16-17,17-18,18-19$, \\
& & 25 & 125 & $18-20,20-21$ \\
\hline $20-25$ & 9 & 102 & 520 & \\
\hline SUM: & 36 & \multicolumn{3}{|}{} \\
\hline
\end{tabular}

\subsection{The proposed problem and related methodology}

In the relevant literature $[32,33]$, authors who intensively study corrosion and its impact on ship structures have proposed a model describing corrosion loss, denoted as $d(t)$, at the observed time $t$, as a power function of time $t$ expressed in years. These models usually start from the assumption that the time when the corrosive processes take influence is known, i.e., when the corrosive wear of the observed metal stricture begins. As a result, the linear corrosion model can be represented in the following form:

$$
d(t)=\left\{\begin{array}{cc}
c_{1}\left(t-T_{c l}\right)^{c_{2}}, & t>T_{c l} \\
0, & \text { otherwise }
\end{array}\right.
$$

where $d(t)$ describes the corrosion depth, measured in $\mathrm{mm}$ or $\mathrm{nm}$. The exploitation time, i.e., the moment of corrosion depth identification is denoted by $t$, while the time moment after which corrosive processes occur is denoted by $T_{c l}$. The positive real coefficients of the model are $c_{1}$ and $c_{2}$. The coefficient $c_{1}$ corresponds to the value of the corrosion rate and is measured in $\mathrm{mm} / \mathrm{years}$ or $\mathrm{nm} / \mathrm{months}$. The coefficient $c_{2}$ regulates the influence of time on the depth of corrosion in the model, and as suggested by Paik et. al. in [9], its usual values are 1 or 1/3. In this paper, due to the assumption that the metal plates are protected by an anti-corrosive coating that guarantees protection for four years, we assume that $T_{c l}=4$. In addition, the analysis of linear models is performed taking the coefficient $c_{2}=1$, as suggested in the relevant literature [9].

As a consequence of these assumptions, the model shown in (1) is now transformed into the following form:

$$
d(t)=\left\{\begin{array}{cc}
c_{1}(t-4), & t>4 \\
0, & \text { othervise }
\end{array}\right.
$$

where $t$ represents the elapsed time since the beginning of the operation of the ship in which corrosive processes were detected. 
It is known that classification societies prescribe limit values for the percentage wear of metal structural elements of a ship. Guided by these regulations, we focus the analysis on the assessment of the percentage $p(t)$ of corrosion wastage concerning the average initial thickness of the structural bulk carrier. If the average initial structural thickness of the considered group of bulk carriers $\left(\overline{d_{0}}\right)$ is known, then it is possible to determine the value for $p(t)$, in the following way:

$$
p(t)=\frac{d(t)}{\overline{d_{0}}}\left(\text { where } t>T_{c l}\right)
$$

Using a simple mathematical calculation and taking into account formula (2) follows

$$
p(t)=\frac{d(t)}{\overline{d_{0}}}=\frac{c_{1}}{\overline{d_{0}}}\left(t-T_{c l}\right)=p_{0}\left(t-T_{c l}\right)\left(\text { where } t>T_{c l}\right) .
$$

The linear model (4) describes the percentage wear of the metal structure due to the influence of corrosion. The percentage of wear is defined as a function of the exploitation time $(t)$ and the annual percentage rate of wear $\left(p_{0}\right)$, but implicitly also it depends on the average original thickness of the metal plate $\overline{d_{0}}$.

\section{Results}

Due to the assumption that corrosion starts after four years of exploitation and based on the expression (4) $T_{c l}=4$ can be incorporated in the linear model, resulting in expression for estimation of annual percentage wastage $p_{0}$ for the IBPs of the investigated fuel oil tanks on 36 ships surveys, i.e.,

$$
p_{0}=\frac{d(t)}{(t-4) \overline{d_{0}}}=\frac{p(t)}{(t-4)}
$$

under restriction $t>4$.

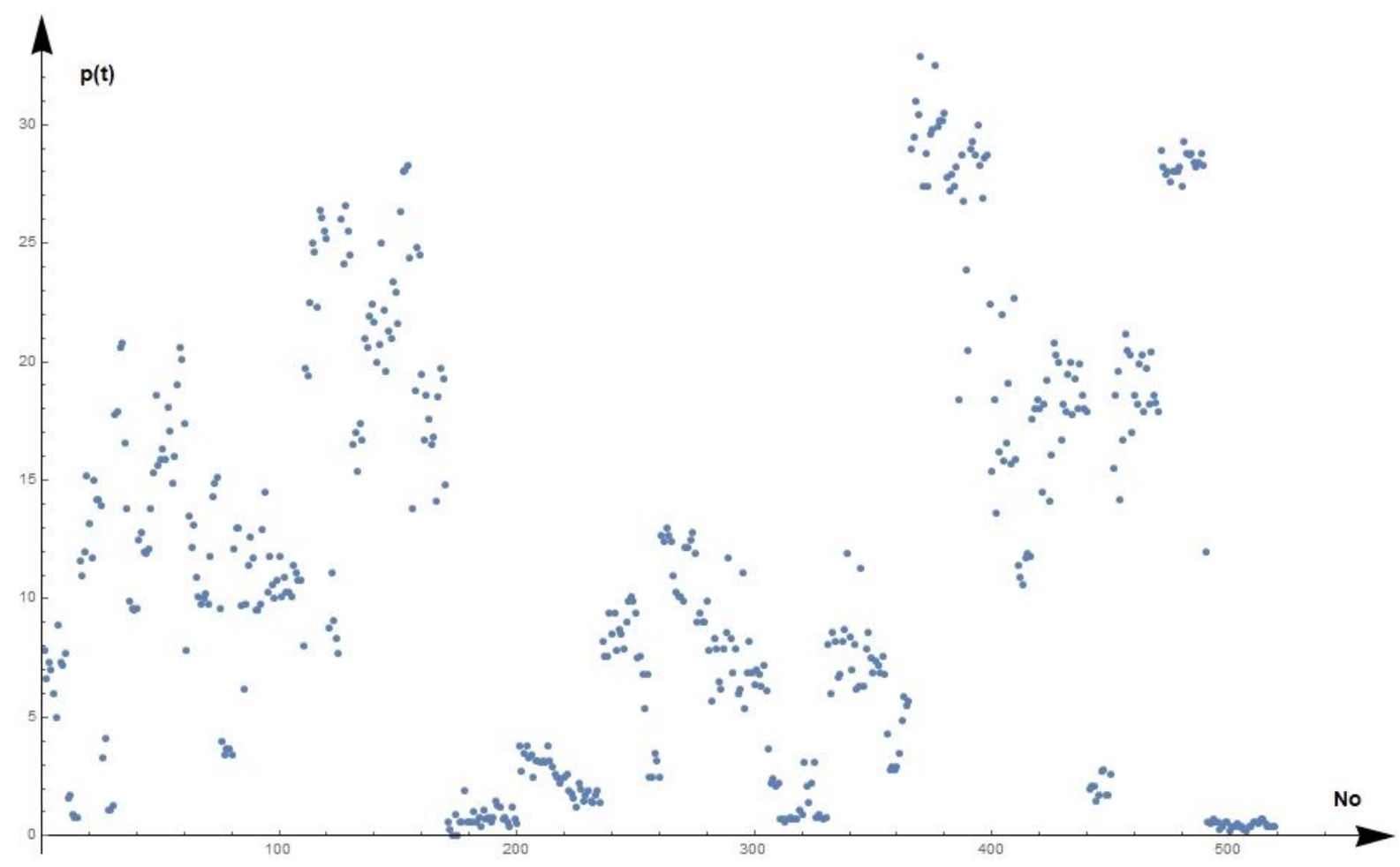

Fig. 2 The available 520 input data sets obtained for IBP

The empirical database is graphically shown in Figure 2. Each of the 520 data set calculated percentage wear plate thicknesses is associated with one point in Figure 2. The percentage wear 
rates are calculated relative to the observed original metal plate thicknesses, taking into account the average thickness of each observed section. These empirical data served to form a linear model and determine the functional dependence of the model parameters. Based on the analysis, it is possible to determine the time moments when the observed thicknesses of metal plates are subject to critical (i.e., prescribed limit) values of percentage wear as a consequence of corrosion.

Table 4. shows some of the standard descriptive statistics for 520 empirical input set data expressed as the percentage of corrosion wastage and later subjected to analysis in this paper. Empirical data were grouped based on the original thickness of the metal plate into three sets: original thicknesses from $15 \mathrm{~mm}$ to $17 \mathrm{~mm}, 17 \mathrm{~mm}$ to $19 \mathrm{~mm}$, and $19 \mathrm{~mm}$ to $23 \mathrm{~mm}$. For each set of empirical data, the relevant numerical characteristics, as well as the values of the first and third percentiles, are given, which will later be used in the analysis of linear models.

Table 4 The descriptive statistics of the IBP empirical data

\begin{tabular}{|l|l|l|l|l|l|}
\hline \multicolumn{2}{|c|}{$15 \leq \boldsymbol{d}_{\mathbf{0}}<\mathbf{1 7}$} & \multicolumn{2}{c|}{$17 \leq \boldsymbol{d}_{\mathbf{0}}<\mathbf{1 9}$} & \multicolumn{2}{c|}{$19 \leq \boldsymbol{d}_{\mathbf{0}} \leq \mathbf{2 3}$} \\
\hline Statistic & Value & Statistic & Value & Statistic & Value \\
\hline Sample Size & 170 & Sample Size & 250 & Sample Size & 100 \\
\hline Mean & 14.2553 & Mean & 9.0276 & Mean & 13.344 \\
\hline Min & 0.8 & Min & 0 & Min & 0.2 \\
\hline Max & 28.3 & Max & 32.9 & Max & 29.3 \\
\hline Std. Deviation & 6.66699 & Std. Deviation & 8.92447 & Std. Deviation & 10.8267 \\
\hline $25 \%$ (Q1) & 9.8 & $25 \%(Q 1)$ & 2.2 & $25 \%(Q 1)$ & 0.6 \\
\hline $75 \%$ (Q3) & 19.4 & $75 \%(Q 3)$ & 11.7 & $75 \%(Q 3)$ & 20.3 \\
\hline
\end{tabular}

In some of the related papers presented by, Ivošević et al. [28, 31] a complete database of 570 empirical data for corrosion wear in the structural area of IBP expressed in mm was used. Due to the incompleteness of the database, some measurements were eliminated from consideration, which resulted in a reduced database of 520 measurements, which were used for this work. All measurements with a corrosion depth of less than $0.3 \mathrm{~mm}$ were eliminated because these values can be considered negligible and treated as the absence of corrosion. In addition, all measurements for which no data on the original thickness of the metal plate was registered were rejected. These 520 remaining data sets related to the recorded corrosion depths were converted into appropriate percentage values. As the thickness of the original plates of the IBP structure varies, these thicknesses were first grouped in three intervals, namely $[15,17)$, $[17,19),[19,23]$, where the boundaries of the interval are expressed in $\mathrm{mm}$. The intervals are numbered in ascending order of the lower bound so that they are associated with the ordinal number $i$, where $i \in\{1,2,3\}$, and the average value of the interval is denoted by $d_{i}$ where $d_{i} \in$ $\{16,18,21\}$. Each original thickness of the observed steel plate can be associated with one of the previously formed intervals. In this way, it is possible to determine the total number of samples belonging to the formed interval $i$ and $i \in\{1,2,3\}$. The average value of the original thickness of the IBPs $\overline{d_{0}}$ is calculated according to the form for grouped data as follows

$$
\overline{d_{0}}=\frac{1}{N} \sum_{i=1}^{3} d_{i} n\left(d_{i}\right)
$$

where $n\left(d_{i}\right)$ represents the frequency of $d_{i}, i \in\{1,2,3\}$.

The total number of samples, i.e., the measured corrosion depths, which correspond to the observed interval of the original steel thicknesses, is denoted by $N$, and since this value is known it is possible to calculate the value of the original average metal plate thickness $\overline{d_{0}}$. Based on that, empirical data expressed in $\mathrm{mm}$ are easily further transformed into the corresponding 
percentages. The percentages obtained as described and presented in Table 2. were subjected to additional analysis and fitting of the linear models described by expressions (4) and (5), thus obtaining the following analytical models of corrosion for each considered interval:

$$
\begin{aligned}
& p_{1}^{Q_{1}}(t)=0.51508(t-4) \\
& p_{2}^{Q_{1}}(t)=0.09680(t-4) \\
& p_{3}^{Q_{1}}(t)=0.44615(t-4) \\
& p_{1}^{M}(t)=1.06222(t-4) \\
& p_{2}^{M}(t)=0.65046(t-4) \\
& p_{3}^{M}(t)=0.67599(t-4) \\
& p_{1}^{Q_{3}}(t)=1.48069(t-4) \\
& p_{2}^{Q_{3}}(t)=1.10056(t-4) \\
& p_{3}^{Q_{3}}(t)=1.27165(t-4)
\end{aligned}
$$

where $t \geq 4$.

In the linear models (7)-(15), the lower index, which takes the values 1,2, and 3, represents the ordinal number of the observed interval, as mentioned earlier. The notation that appears in the exponent shows the set of empirical data that was analyzed. Namely, for each observed interval, the corresponding set of empirical data is divided into three subgroups, by separately observing the values from the first quartile, mean values, and values from the third quartile (Table 4.). In this way, for all three intervals $[15,17),[17,19),[19,23]$, three linear models were formed that reflects the behavior of percentage wear if the lowest (models (7)-(9)), mean (models (10)-(12)), and highest values (models (13)-(15)) are observed. The model coefficients in front of the brackets represent the annual percentage rate of corrosion growth.

The formed linear models (7)-(15) are graphically represented in Figure 3. as linear functions. Figure 3. also shows the empirical data grouped by the elapsed time of exploitation, expressed in years.

Based on the graphical representation and expressions shown in linear models (7)-(15), different percentages of wear behavior are observed, depending on the original thickness of the steel plate. It is worth mentioning that the minimal percentage of corrosion wear is observed on plates with original thickness between $17 \mathrm{~mm}$ and $19 \mathrm{~mm}$.

Legislation used by some classification societies states that the critical values of the percentage loss of entire structural areas are 10\%. Additionally, this paper analyses the limit value of $15 \%$ loss. Guided by these regulations and based on linear regression, it is possible to estimate the time in the operation of ships, when individual structures reach the prescribed limit values and are practically unusable. Of particular importance is the determination of the time when the estimated maximum percentage of corrosion wear reaches these critical values. Namely, as soon as one of the structures shows a tendency to reach the limit, it can be said that the whole ship is unusable and that it is necessary to either repair and replace extremely damaged parts or even ultimately eliminate the ship from use. 
Špiro Ivošević, Nataša Kovač, Nikola Momčilović, Goran Vukelić
Analysis of corrosion depth percentage on the inner bottom plates of aging bulk carriers with an aim to optimize corrosion margin

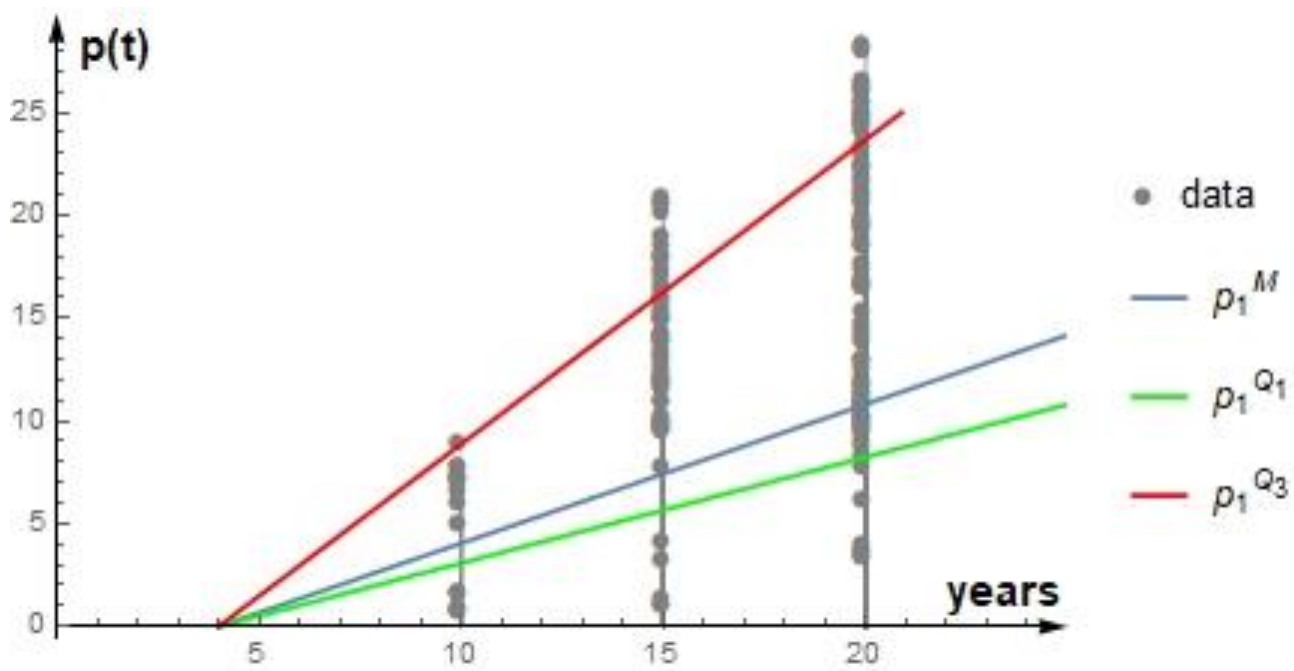

a)

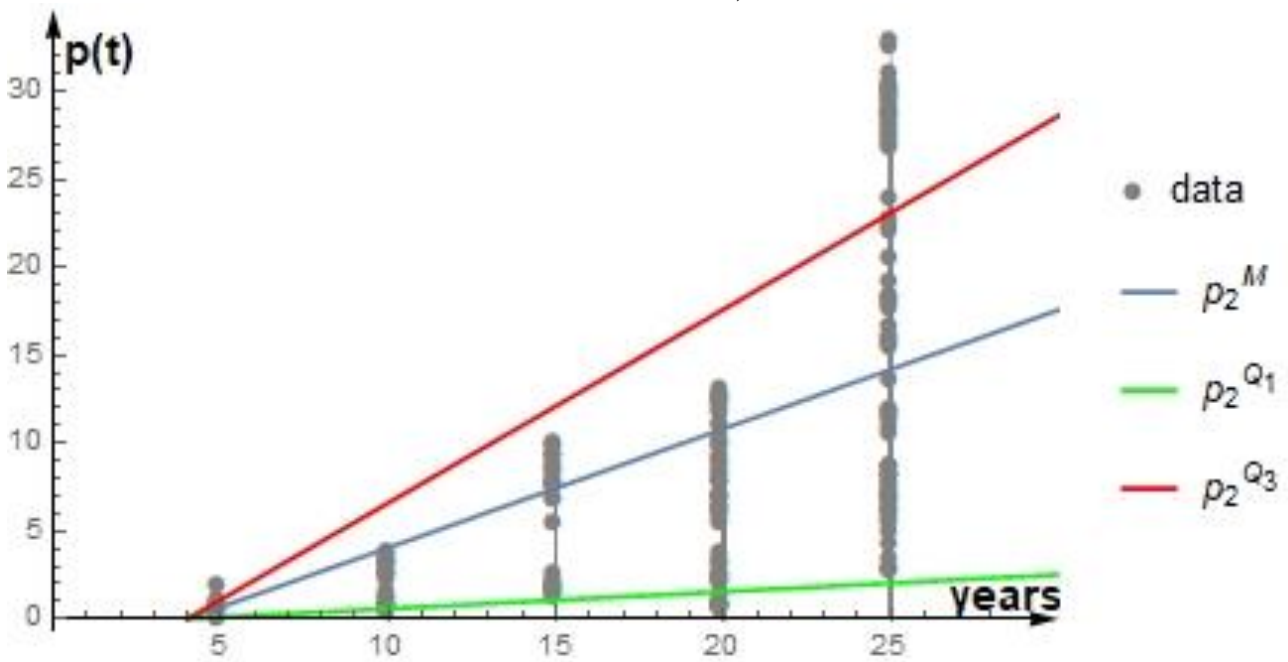

b)

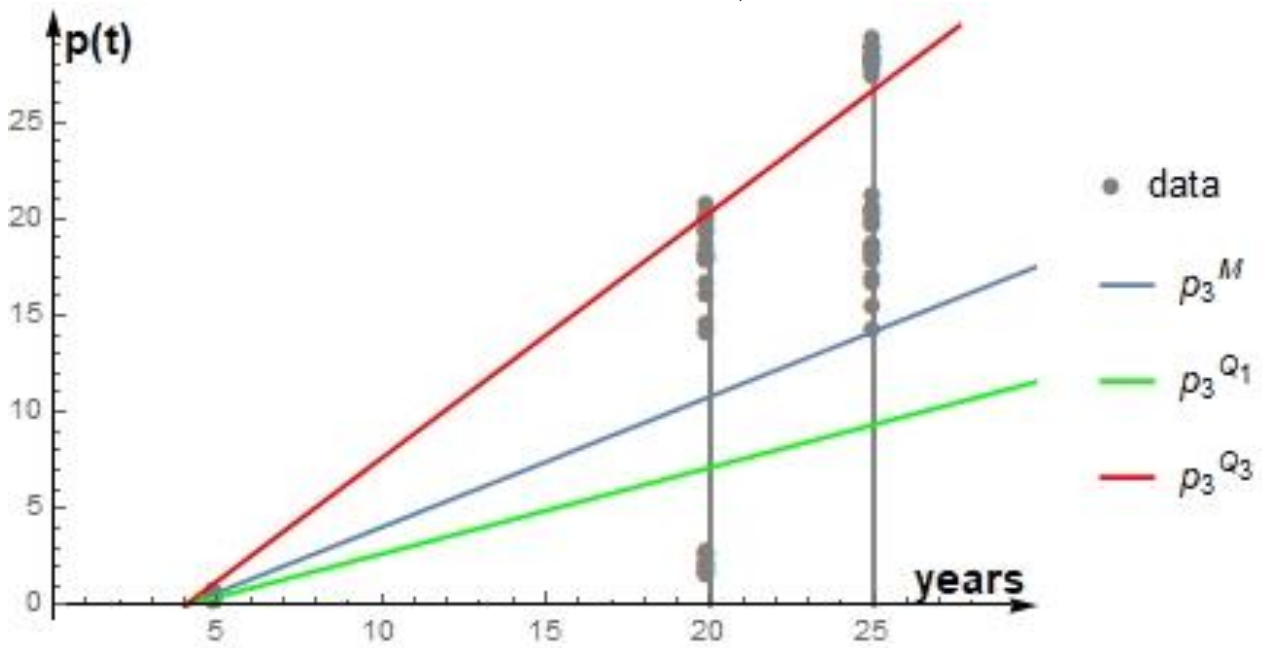

c)

Fig. 3 Linear models for minimal (a), mean (b), and maximal (c) percentage of corrosion wear as a function on $t$

Based on this consideration, the further analysis included only linear models (13)-(15) which refer to the data from the third quartiles, i.e., to the data showing the extreme values of the percentage wear of the metal plate, from each observed thickness interval. By equating the 
expressions that appear in models (13)-(15) with critical values of $10 \%$ and $15 \%$, respectively, the critical values for $t$ expressed in years are obtained, and Table 5. is formed. This table shows time moments when the individual thicknesses of the original steels plates from the IBP structure reach their critical percentage wear values.

Table 5. Time when the critical values of percentage wear are reached

\begin{tabular}{|l|c|c|c|}
\hline & Original thickness intervals & $\boldsymbol{p}(\boldsymbol{t})=\mathbf{1 0} \%$ & $\boldsymbol{p}(\boldsymbol{t})=\mathbf{1 5} \%$ \\
\hline $\boldsymbol{p}_{\mathbf{1}}^{\boldsymbol{Q}_{3}}(\boldsymbol{t})$ & {$[15,17)$} & $t=10.8$ years & $t=14.1$ years \\
\hline $\boldsymbol{p}_{\mathbf{2}}^{Q_{3}}(\boldsymbol{t})$ & {$[17,19)$} & $t=13.1$ years & $t=17.6$ years \\
\hline $\boldsymbol{p}_{\mathbf{3}}^{Q_{3}}(\boldsymbol{t})$ & {$[19,23]$} & $t=11.9$ years & $t=15.8$ years \\
\hline
\end{tabular}

The observed linear models (13)-(15) and the predefined critical values of $10 \%$ and $15 \%$ are shown in Figure 4. For example, for thicknesses of original steels from the interval $[17,19)$, the predicted time to reach the critical value of $10 \%$ percentage wear is 13.1 years, while the same value of $10 \%$ in the case of steel thickness $[15,17)$ reaches in 10.8 years.

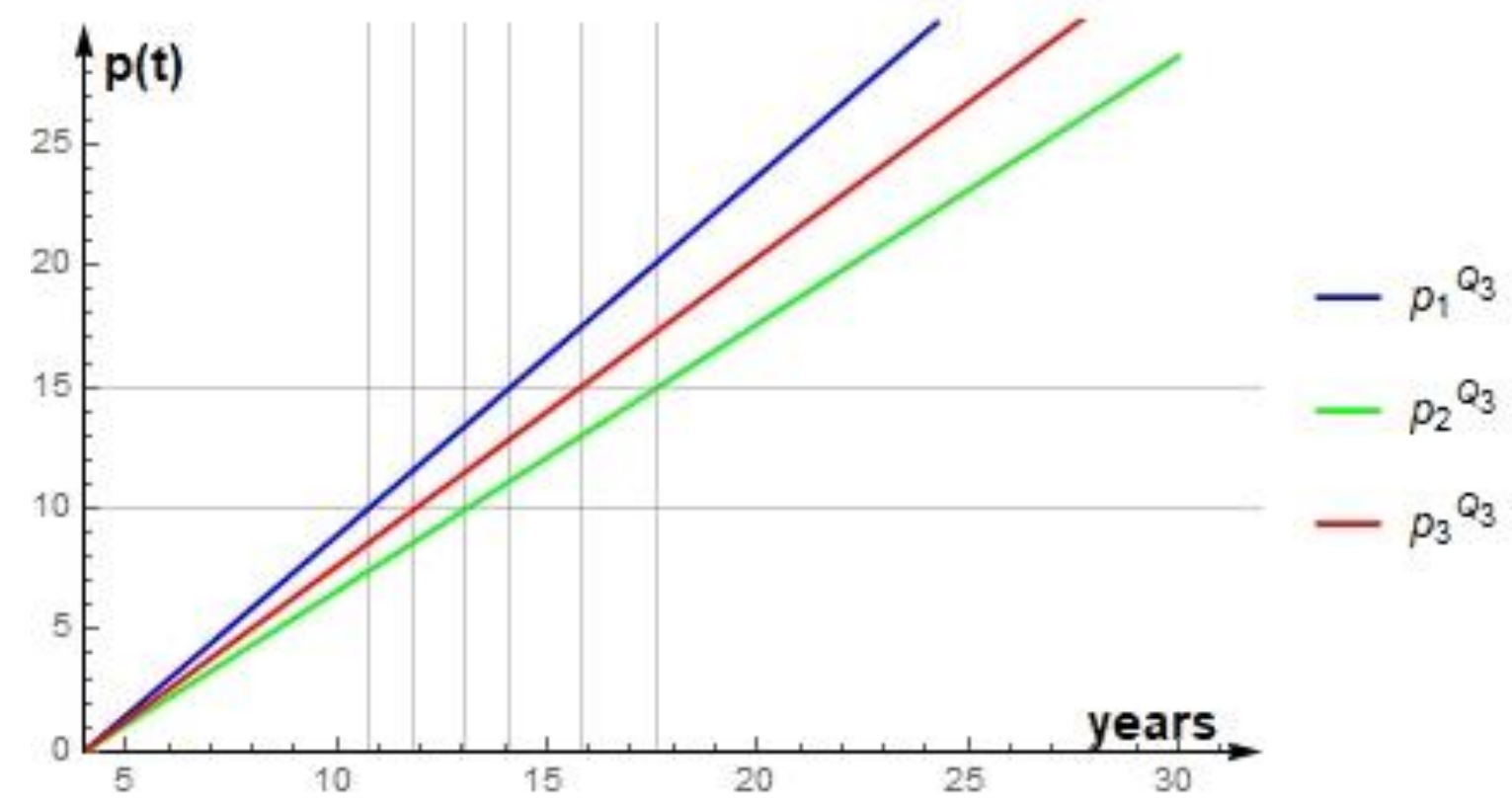

Fig. 4 Critical values for maximal percentage wear of IBP

From Figure 4. it can be observed that the corrosive processes on IBP are very intense so that the recommendation that the entire structural area should be replaced could occur between 10 and 13 years of usage. Considering that the projected life of the ship is 20 to 25 years, it becomes clear that from the point of view of the IBP area, it is not possible to reach these time intervals, and that the IBP area is one of the structural areas showing the most intensive tendencies to corrosion.

Figure 5. shows empirical data on the wear of IBP fuel oil tanks of aging bulk carriers taking into account the different built-in thicknesses of steel plates. For bulk carriers aged 20 years, a complete empirical database is used, so that it was possible to consider an entire curve that corresponds to each observed thickness interval. From the graphs, it can be concluded that for thicknesses of $15-17 \mathrm{~mm}$ and $19-23 \mathrm{~mm}$, there is a trend of increasing corrosive wear. However, in the case of 17-19 mm thicknesses, a decrease in the wear speed of metal plates is evident. For other groups of ships aged 5, 10, 15, and 25 years, incomplete empirical databases 
are observed. To compensate for the non-existent data and form complete curves, the results from the regression analysis were used. In Figure 5., the empirical mean values of the corrosion depth estimates are plotted in solid lines, while the predicted values obtained by regression analysis (see formulas 10-12) are represented by dashed lines.

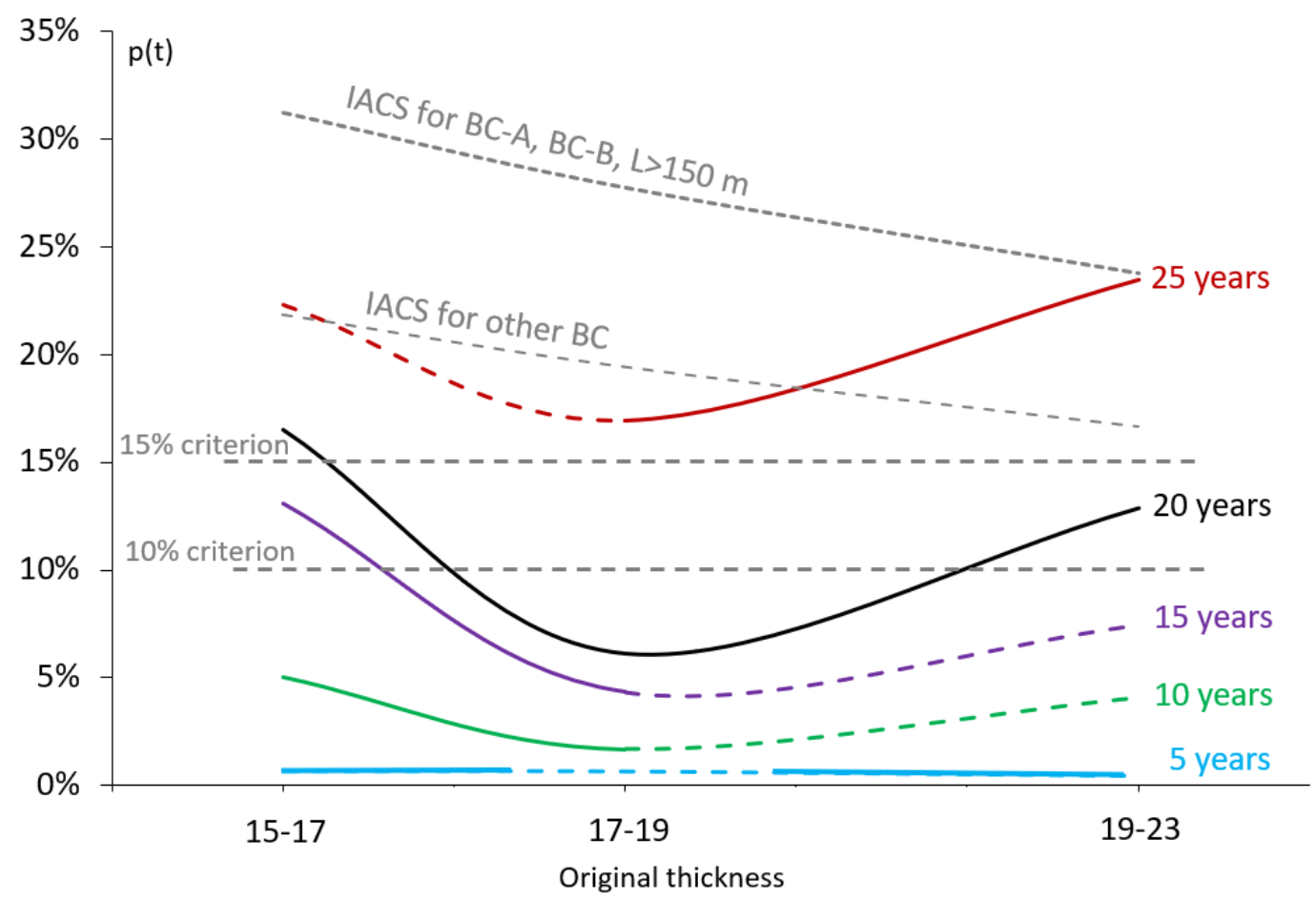

Fig. 5 Simultaneous presentation of IBP percentage loss curves and prescribed IACS critical values

It can be seen from Figure 5. that the prescribed IACS margins can be applied only for steel plate thicknesses of 19-23 mm and for ships that have been in usage for 25 years. For the remaining two IBP thickness intervals, this assumed corrosion margin is too large. Considering the above criteria, it becomes obvious that the corrosion margin prescribed by the IACS rules is overestimated. However, if stricter criteria are considered that consider a $10 \%$ or $15 \%$ reduction in entire areas of IBP, a large amount of IBP would be replaced before the projected 25 operational years are reached.

From the conducted research, it is concluded that there is a possibility of optimizing the thicknesses of the built-in plates of IBP in terms of achieving optimal ship design and better energy efficiency of ships.

\section{Conclusion}

This paper investigates a linear model for estimating the percentage of corrosion wear of IBP of bulk carrier fuel oil tanks concerning the build-in plate thickness. The percentage of wear is considered as a function of the service life with the initial assumption that corrosive coatings protect the metal plate for four years, after which corrosive processes occur. Based on 520 empirical input set data of measured corrosion depth values expressed in $\mathrm{mm}$ and based on build-in plate thicknesses grouped into three disjoint categories, an equivalent empirical database was obtained describing the percentage of the corrosive wear of IBPs of bulk carriers.

Conventional linear models for corrosive processes were applied to each of the three considered groups of original steel plate thicknesses. Within each of these groups, linear models that best describe minimum, average, and maximum corrosive processes are fitted. This procedure has formed, in total, 9 models that can predict the percentage of wear of each category of the thickness of the original plate depending on the time of exploitation. 
From the conducted analyses of three considered ranges of build-in plate thickness, it could be concluded that, during the exploitation period, IBP with thickness ranging between $17 \mathrm{~mm}$ and $19 \mathrm{~mm}$ is showing less corrosion waste percentage comparing to the one produced by thicknesses having interval of $15-17 \mathrm{~mm}$ and $19-23 \mathrm{~mm}$.

More precisely, based on the conducted research, it is possible to optimize the corrosion margin during the process of designing a ship. This can be concluded due to a large part of the steel surface do not reach 25 years of service of life, for which it was originally designed. The optimization of the corrosion margin has just left the potential for lighter ships and thus hurt the energy efficiency of bulk carriers.

These results need further investigation to check what is the real source of such distribution, whether it is related to the particular part and exploitation of the structure or other cause.

Analogous research can be conducted on extended databases with more vessels, measuring thickness data and different input data of ship's operation and maintenance activities. The second direction of research can be carried out by analyzing more complex nonlinear models of corrosive processes.

\section{Acknowledgement}

This research work has been supported by the approved Thickness Measurement Company - INVAR-Ivošević Company. Some more information about the Company can be found at URL: http://www.invar.me/index.html. Namely, the data collected and systematized during the last twenty-five years by the Company operators and experts have been included in the presented probabilistic analysis of the corrosion effects to the analyzed group of aged bulk carriers. Last decades the INVAR-Ivošević Company completed ultrasonic thickness measurements reports for vessels under the recognized classification societies such as LR, BV, DNV, GL, RINA, ABS, and ClassNK. Currently, more than four hundred vessels, are being inspected by the Company.

\section{REFERENCES:}

[1] Vukelić, G., Vizentin, G., Brnic, J., Brcic, M., Sedmak, F., L, Long-Term Marine Environment Exposure Effect on Butt-Welded Shipbuilding Steel, Journal of Maritime Science and Engineering, 2021, 9(5), 491 https://doi.org/10.3390/jmse9050491

[2] Roberts, S.E., Marlow, P.B., Casualties in dry bulk shipping (1963-1996), Marine Policy, vol. 26, 2002, pp. 437-450. https://doi.org/10.1016/S0308-597X(02)00024-6

[3] Bulk carrier casualty report, IMO, MSC 83/INF.6, 3 July 2007.

[4] Chichi, D., Garbatov, Y., Retrofitting analysis of tanker ship hull structure subjected to corrosion, Brodogradnja/Shipbuilding, Volume 70, Number 2, 2019, https://doi.org/10.21278/brod70205

[5] Guedes Soares, C. and Garbatov, Y., 1998, "Reliability of maintained ship hull girders subjected to corrosion and fatigue", Structural Safety, 20, (3), pp. 201-219. https://doi.org/10.1016/S0167$\underline{4730(98) 00005-8}$

[6] Rudan, S., Garbatov, Y. and Guedes Soares, C., 2003, "Fatigue damage assessment of side shell longitudinal based on spectral approach", Brodogradnja/Shipbuilding, 51, pp. 227-234.

[7] Jurisic, P., Parunov, J. and Garbatov, Y., 2017, "Aging Effects on Ship Structural Integrity", Brodogradnja/Shipbuilding, 68, (2), pp. 15-28. https://doi.org/10.21278/brod68202

[8] Mohammad Reza Zareei , Mehdi Iranmanesh, Reliability-based inspection planning of the ship structure exposed to fatigue damages, Brodogradnja/Shipbuilding, Volume 69 Number 2, 2018, https://doi.org/10.21278/brod69208

[9] Paik, J.K., Kim, S.K., Lee, S.K. A probabilistic corrosion rate estimation model for longitudinal strength members of bulk carriers, Ocean Engineering, 1998, 25(10), 837-860. https://doi.org/10.1016/S0029$\underline{8018(97) 10009-9}$ 
Špiro Ivošević, Nataša Kovač, Nikola Momčilović, Goran Vukelić
Analysis of corrosion depth percentage on the inner bottom plates of aging bulk carriers with an aim to optimize corrosion margin

[10] Paik, J.K., Lee, J.M., Park, Y.I., Hwang J.S., Kim, C.W., Time-variant ultimate longitudinal strength of corroded bulk carriers, Marine Structures, vol. 16, 2003, pp. 567-600. https://doi.org/10.1016/j.marstruc.2004.01.003

[11] Paik, J.K., Thayamballi, A.K., Park, Y.I., Hwang, J.S., A time-dependent corrosion wastage model for bulk carrier structures, International Journal of Maritime Engineering, vol.145, Part A2, 2003, pp. 61-87. https://doi.org/10.3940/rina.ijme.2003.a2.18031

[12] Caridis, P., 2001, Inspection, Repair and Maintenance of Ship Structures: Wetherby.

[13] Garbatov, Y. and Guedes Soares, C. "Maintenance Planning for the Decks of Bulk Carriers and Tankers". In: Reliability and risk of structures, infrastructures and engineering systems. H. Furuta, D. M. Frangopol and M. Shinozuka, editors. London, UK: Taylor \& Francis Group, 2010, pp. 3517-3524.

[14] Paik, J.F. ; Brennan, F. ; Carlsen, C.A.; Daley, C. ; Garbatov, Y.; Ivanov, L.; Rizzo, C.; Simonsen, B.C.; Yamamoto, N.; Zhuang, H.Z. Report of Committee V.6 Condition Assessment of Aging Ships, 16th International Ship and Offshore Structures Congress, 20-25 August 2006, Southampton, UK

[15] Guedes Soares, C..; Garbatov, Y.; Zayed, A. Effect of environmental factors on steel plate corrosion under marine immersion conditions, Corrosion Engineering Science and Technologies, 2011, 46, 524-541. https://doi.org/10.1179/147842209X12559428167841

[16] Paik, J.K.; Thayamballi, A.K.; Park, Y.I.; Hwang, J.S. A time-dependent corrosion wastage model for seawater ballast tank structures of ships, Corrosion Science, 2004, 46(2), 2004, 471-486. https://doi.org/10.1016/S0010-938X(03)00145-8

[17] Yamamoto, N.; Ikagaki, K.A. Study on the Degradation of Coating and Corrosion on Ship's Hull Based on the Probabilistic Approach, Journal of Offshore Mechanics and Arctic Engineering, 1998. 120, 121-128. https://doi.org/10.1115/1.2829532

[18] Guo, J.; Wang, G..; Ivanov, L.; Perakis, A.N. Time-varying ultimate strength of aging tanker deck plate considering corrosion effect, Marin Structure, 2008, 21(4), 402-419. https://doi.org/10.1016/j.marstruc.2008.03.002

[19] Garbatov, Y.; Guedes Soares, C.; Wang, G. Non-linear time dependent corrosion wastage of deck plates of ballast and cargo tanks of tankers. In Proceedings of the 22nd International Conference on Offshore Mechanics and Arctic Engineering, OMAE 2005-67579, Halkidiki, Greece, 12-17th June, 2005. https://doi.org/10.1115/OMAE2005-67579

[20] Melchers, R.E., Probabilistic model for marine corrosion of steel for structural reliability assessment, Journal of Structural Engineering, 2003, 129 (11), 1484-1493. https://doi.org/10.1061/(ASCE)07339445(2003)129:11(1484)

[21] Hussein, A. W.; Teixeira, A. P.; Soares, C.G., Impact of the new common structural rules on the reliability of a bulk carrier, Advance in Marine Structures- Proceedings of MARSTRUCT 2007, The 1st International Conference on Marine Structures, Glasgow, United Kingdom, 2007, pp. 529-538.

[22] Ančić, I, Perčić, M, Vladimir, N. “Alternative power options to reduce carbon footprint of ro-ro passenger fleet: A case study of Croatia", Journal of Cleaner Production, 271, 2020, 122638. https://doi.org/10.1016/j.jclepro.2020.122638

[23] Kalajdzic M., Momcilovic N.: A Step Toward Preliminary Design of Seagoing Multi-Purpose Cargo Vessels, Brodogradnja/Shipbuilding, 2020, Vol. 71, No. 2, pp 75 - 89. https://doi.org/10.21278/brod71205

[24] IMO MEPC.304 (72), Resolution MEPC.304(72), 2018. https://doi.org/10.1002/wea.2886

[25] IMO Resolution MEPC.203 (62), 2011.

[26] MO MEPC 75, Amendments to MARPOL Annex VI, Virtual Session, 16-20 November 2020.

[27] IACS, Common Structural Rules for Bulk Carriers and Oil Tankers, 2021.

[28] Ivošević, Š.; Meštrović, R..; Kovač, N. Probabilistic estimates of corrosion rate of fuel tank structures of aging bulk carriers, International Journal of Naval Architect and Ocean Engineering, 2019, 11(1), 165177. https://doi.org/10.1016/j.ijnaoe.2018.03.003

[29] Ivošević, Š.; Meštrović, R.; Kovač, N.: An approach to the probabilistic corrosion rate estimation model for inner bottom plates of bulk carriers, Brodogradnja/Shipbuilding. 2017, 68(4), 57-70 https://doi.org/10.21278/brod68404

[30] Ivošević, Š.; Meštrović, R.; Kovač,: N. A comparison of some multi-parameter distributions related to estimation of corrosion rate of aging bulk carriers. In Proceedings of 7th International Conference on Marine Structures, CRC Press, Dubrovnik, Croatia, 6-8, May 2019, 403-410. https://doi.org/10.1201/9780429298875-47 
[31] Ivošević, Š.; Meštrović, R.; Kovač, N.: A Probabilistic Method for Estimating the Percentage of Corrosion Depth on the Inner Bottom Plates of Aging Bulk Carriers, Journal of Marine Science and Engineering, 2020, 8(6): 442, https://doi.org/10.3390/jmse8060442

[32] Qin, S.; Cui, W. Effect of corrosion models on the time-dependent reliability of steel plated elements, Marine Structure, 2003, 16, 15-34. https://doi.org/10.1016/S0951-8339(02)00028-X

[33] Paik, J.K.; Thayamballi, A.K. Ultimate strength of aging ships, Journal of Engineering for the Maritime Enviromental, 2002. 1(1), 57-77. https://doi.org/10.1243/147509002320382149

Submitted: $\quad 30.08 .2021$ S S S $\quad$ Siro Ivošević, University of Montenegro, Faculty of Maritime Studies Kotor, Put I Bokeljske brigade 44, Kotor, Montenegro; spiroi@ucg.ac.me

Accepted: $\quad$ 21.09.2021. Nataša Kovač, University of Donja Gorica, Faculty of Applied Sciences, Oktoih 1, Donja Gorica, Podgorica, Montenegro; natasa.kovac@udg.edu.me Nikola Momčilović, Faculty of Mechanical Engineering, University of Belgrade, Kraljice Marije 16, Beograd, Serbia, nmomcilovic@mas.bg.ac.rs Goran Vukelić, University of Rijeka, Faculty of Maritime Studies, Studentska 2, Rijeka, Croatia; goran.vukelic@pfri.uniri.hr 